\title{
The Necessity of Philosophy in the Exercise Sciences
}

\author{
Matthew Hickson
}

Department of Kinesiology, Mississippi State University, Starkville, MS 39759, USA; matthickson91@yahoo.com

Received: 2 May 2019; Accepted: 29 July 2019; Published: 7 August 2019

\begin{abstract}
The pervasive and often uncritical acceptance of materialistic philosophical commitments within exercise science is deeply problematic. This commitment to materialism is wrong for several reasons. Among the most important are that it ushers in fallacious metaphysical assumptions regarding the nature of causation and the nature of human beings. These mistaken philosophical commitments are key because the belief that only matter is real severely impedes the exercise scientist's ability to accurately understand or deal with human beings, whether as subjects of study or as data points to be interpreted. One example of materialist metaphysics is the assertion that all causation is physical- one lever moving another lever, one atom striking another atom, one brain state leading to another (Kretchmer, 2005). In such a world, human life is reduced to action and reaction, stimulus and response and as a result, the human being disappears. As such, a deterministic philosophy is detrimental to kinesiologists' attempts to interpret and understand human behavior, for a materialistic philosophy, must ignore or explain away human motivation, human freedom and ultimately culture itself. In showing how mistaken these philosophic commitments are, I will focus on the sub-discipline of sport psychology for most examples, as that is the field of exercise science of which I am paradigmatically most familiar. It is also the field, when rightly understood that straddles the "two cultures" in kinesiology (i.e., the sciences and the humanities). In referencing the dangers of the materialistic conception of human beings for sport psychology, I will propose, that the materialist's account of the natural world, causation and human beings stems from the unjustified and unnecessary rejection by the founders of modern science of the Aristotelian picture of the world (Feser, 2012). One reason that this mechanistic point of view, concerning human reality has gained ground in kinesiology is as a result of a previous philosophic commitment to quantification. As philosopher Doug Anderson (2002) has pointed out, many kinesiologists believe that shifting the discipline in the direction of mathematics and science would result in enhanced academic credibility. Moreover, given the dominance of the scientific narrative in our culture it makes it very difficult for us not to conform to it. That is, as Twietmeyer (2015) argued, kinesiologists do not just reject non-materialistic philosophic conceptions of the field, we are oblivious to their possibility. Therefore, I will propose two things; first, Aristotelian philosophy is a viable alternative to materialistic accounts of nature and causation and second, that Aristotle's holistic anthropology is an important way to wake kinesiologists from their self-imposed philosophic slumber.
\end{abstract}

Keywords: exercise science; philosophy; sport psychology; materialism; Aristotle; causation and nature

\section{Introduction}

This paper will argue that philosophy is necessary in order to be a good exercise scientist. Although often unconscious and largely unacknowledged by exercise scientists, materialism is the prevailing philosophy in the field. I will claim, this philosophic commitment is problematic for three reasons. First, the materialist's anthropology is wrong in its assertion that the human being is reducible to mere matter. Second, materialisms endorsement of casual determinism ultimately denies 
the possibility of human freedom, values and consciousness. Third, in taking the view that nature is inert and external to particular beings it must follow that human life is devoid of any inherent purpose or goal-directedness. To the extent that the exercise scientists buys into materialist arguments such as these, it calls into question the ethical soundness of their practice and research, as well as its supposed truth in terms of application to the lived experience of human beings. I will propose Aristotelian philosophy as a viable alternative for exercise science and the perfect antidote to the problems posed by materialism. Most specifically I will draw upon Aristotle's argument for anthropological holism and his anti-mechanistic, materialistic accounts of nature and causation.

\section{Refuting Materialistic Accounts of Nature}

The picture of nature that predominates in the hard sciences and as a result, exercise science is staunchly materialistic. It is physiology, chemistry and physics that are the heart of kinesiology, because they measure the material world and the material world is all that exists. For example, in sport psychology the relationship between anxiety and performance is often viewed mechanistically (Wilson, 2008 [1]). Broader accounts which view anxiety as part of human beings' ontological condition have been largely overlooked (Ronkainen and Nesti, 2015 [2]). The ontological approach proposed by Ronkainen and Nesti, views anxiety as a concomitant of our freedom to make choices and sees it as a challenge that must be confronted by the athlete. In contrast, the mechanistic approach attempts to eliminate rather than understand the influence of anxiety. In doing so it places a heavy emphasis on techniques and limits the athlete's personal responsibility. What follows from this mechanistic point of view, is the assumption that the nature of anything is not intrinsic to it. Instead "nature" is seen as something external to the objects of our experience as it is to ourselves as human beings. As philosopher Joe Sachs (1995) explained, from a mechanistic point of view, "nature is merely a name for the collective sum of things" [3] (p. 19). This view replaced the Aristotelian account of active powers within things, with the idea that natural phenomena are essentially passive. That is, there is no intentional direction to a thing which is internal to its own being. An acorn for instance, is not directed by its own internal organization and nature towards becoming an oak, instead physical laws are imposed upon it from the outside (Feser, 2012 [4]). As such, materialistic philosophy leads many hard scientists to falsely predicate that all events in the natural world occur accidentally, by which they mean not chaotically, but without any meaning, order or purpose. As Sachs (1995) described:

The picture of the world assumed by the materialist physicist is of atoms and void there can be no cosmos, but only infinite emptiness, no life but only the accidental rearrangement of matter. [3] (p. 17)

In contrast, Aristotle viewed nature in a non-derivative sense. He thought that things possess natures of their own. This is most obvious with living things which are organized, and goal oriented. Contrary to the materialist conception of nature, Aristotle saw it as something active and dynamic instead of merely inert.

Yet, if the Aristotelian position is correct then, the regularity that we find in the cosmos implies a necessary connection between cause and effect. Living things have real and inherent causative power. A things own nature not merely the laws of nature is the source of motion and rest within living organisms (Sachs, 2001 [5]). Of course, critics might insist that materialistic, hard scientists' attribution of inertia to all things within the natural world is not meant to be antagonistic but merely methodological. It is read into the scientific method to fulfil a specific purpose. To use the tools of the scientific method to pursue a better understanding of the natural world. Moreover, haven't the scientific discoveries of the last several centuries justified this position? Two responses to this can be offered. First, methodology should not be confused with ontology. To say that the scientific method requires scientists to "remain silent regarding what they cannot measure" and to say "what they cannot measure is unreal" are two very different things. Second, history shows that the materialistic motivation of hard scientists, has not always been merely methodological, nor has it always been benign. 
That is, materialism also allows scientists to treat nature as a mere object that is to be controlled and dominated. This fiction is extremely useful, but the cost is likewise high. This view fails to recognize a fundamental difference between living things and inanimate objects. These differences- so quickly denied and ignored by materialists- are real and profound. For example, unlike living things, inanimate objects don't have the capacity to stop and start themselves. Philosopher of science Mary Midgley (1992) explained the concept of an inert natural world through a common view of the purpose of the scientific project, by referring to a quote from Francis Bacon:

Men ought to make peace among themselves to turn with united forces against the nature of things, to storm and occupy her castles and strongholds. [6] (p. 77)

This mechanistic picture of nature proposed by Bacon, if endorsed, is detrimental for kinesiology. Here is but one key example, if we follow Bacon's commitments through to their conclusion, we would have no principled reason not to limit genetic engineering or even eugenics in the practice of kinesiology. If human beings are merely material there is nothing sacrosanct about them, they are simply one more castle to be "stormed and occupied". As Brown (2009) explained:

Surely there are few of us who would not welcome enhanced memories and immune systems, a prolonged healthy life span, and greater cognitive powers to create and appreciate the lives we have. Their wide availability would go far in remedying the failures of nature (as we see them) and promoting a more just and prosperous society. [7] (p. 135)

Brown's account is overly optimistic in that it overlooks a crucial danger associated with bio-technology. That is, we would come to value athletes in terms of the physical attribute's hard scientists have designed and produced instead of viewing them in terms of their inherent value as human beings. Moreover, what materialist scientists such as Bacon either ignore or fail to realize is if we depersonalize human nature it presents us all, scientists and non-scientists alike with a grave epistemological problem. If there is nothing akin to our human faculties of reason, will, desire and curiosity within the nature of things, then nature becomes utterly incomprehensible. In reducing their subjects to mere insentient lumps of matter, the materialist scientists reduce themselves to mere insentient lumps of matter. It is for this reason that those thinkers who have emphasized the intrinsic, living and animate character possessed by nature have tended to propose that there is a kind of 'rational structure' to the material universe. As C.S Lewis (1967) put it:

Unless all we take to be knowledge is an illusion, we must hold that in thinking we are not reading rationality into an irrational universe but responding to a rationality with which the universe has always been saturated. [8] (p. 89)

Aristotle is again useful for addressing this problem for he argued that human beings are rational animals by nature, which, if true, means that human beings should be able to recognize the correspondence between the rational nature of man and the rationality of nature as such. Moreover, other scholars have argued, scientific inquiry cannot proceed if this correspondence is explicitly denied. Cardinal Joseph Ratzinger (2006) put it this way:

Modern scientific reason quite simply must accept the rational structure of matter and the correspondence between our (human) spirit and the prevailing rational structures of nature as a given, on which its methodology has to be based. [9] (p. 16)

Such claims are not merely another attack by "reactionary clerics" upon progressive scientists. Ratzinger's endorsement of a rational structure inherent to nature is in no way a departure from sound scientific practice. The issue raised is philosophical not theological. The issue raised is also inescapable. As Albert Einstein put it, "what is most incomprehensible about nature is the fact it is comprehensible" (Pieper, 1989 [10] p. 94). This view held by Einstein implies two things. First, that the primary aim of hard scientists ought to be understanding nature, rather than controlling it. Second, 
that there is a basic order to things, which can be understood. Scientific enquiry is dependent upon basic foundational commitments such as these. That is, for scientific research to get off the ground these assertions must be already accepted (at least tacitly) for any scientific research to commence. Philosophy whether materialistic or Aristotelian, whether true or false, is baked into the scientific enterprise. As the philosopher Thomas Nagel (2012) insists:

Materialism is incomplete even as a theory of the physical world, since the physical world includes conscious organisms among its most striking occupants. [11] (p. 45)

As a result, insofar as many exercise scientists uncritically accept materialism and deny any coherent account of human consciousness, they are ill-equipped to accurately describe or understand the animate life and nature of human beings. If Aristotle is right about mans nature, then the contemporary scientific image of human behavior, of neurons firing, causing other neurons to fire ad infinitum (Cave, 2016 [12]) as a comprehensive explanation for human behaviors, thoughts and actions simply doesn't fit the bill. The materialist picture of nature is a convenient tool for initiating the endeavors of the scientific enterprise, but it should not be mistaken for more than it is. As Aristotle told us in his ethics, we should not expect more from a science than what it can give. Scientific research is valuable, but it is also limited. To say that natural science is good does not mean it gives us an all-encompassing view of reality. The scientific method should not be applied haphazardly to the world which we experience. As Sachs (2001) argues:

As long as the sort of explanation is doing pure mathematics with an imaginary world, it is safe from objection, but as soon as it is applied to the experiential world, it becomes subject to perception. [5] (p. 13)

This purely mathematical account is an attempt to deny that anything in the world has specific qualities, rather than mere quantities. It is also an attempt to deny or ignore the reality of the natural scientists themselves, upon whose conscious perception all scientific measurements rely. As such, it makes the perceptual activities common to us all, a matter of skeptical doubt. Yet, our lived experience tells us that qualities like color do in fact exist. Wherever this falsification or simplification of reality is not recognized, the mathematical, mechanical conception of nature should be dismissed as an object of fiction.

Merely explaining away perception as that which takes place entirely through the mechanisms of our sense organs and the events of the nervous system is inadequate. If perception was nothing but a mechanical process in the body, then the things we take in through perception should also be merely material. However, an often-heard phrase in sport shows that this cannot be the case. That is, that the "extra one percent is the difference between success and failure". But in what way could this "extra" $1 \%$ make sense as a material reality. It is asserted that this wholly immaterial idea plays an essential role in motivating athletes because our common experience- despite sophisticated philosophical denialsshows that when we perceive the nature of a thing, we receive that nature in an extra material way. The nature of a thing comes to us as more than the mere sum of its material parts. The human person both in our awareness of ourselves and our awareness of others, is the most obvious example of this truth. As Sachs (2001) insists:

Living comes about just where material bodies cease to explain anything, where they are organized into active wholes. It used to be said that the human body is mostly water whilst the rest of it is $\$ 1.98$ worth of chemicals. Obviously, those materials, which could be collected in a bucket, are transformed when they are a human body, and only form can explain the difference. [5] (p. 18)

A further example of this, would be when we open the shutter on a camera, the mechanism does not enable the camera to see anything (Sachs, 2001 [5]), because sight is more than mechanism. In brief, anything that is merely material doesn't have even the simple sensory capabilities that are common to 
human beings because mechanism and sensation aren't the same thing. As such, perception cannot solely be the physiology of the sense organs (Sachs, 2001 [5]). Physiology is necessary but not sufficient.

Yet, the uncritical acceptance of materialism in exercise science demands that all things can be explained by underlying mechanisms. For instance, in sport psychology it is common to reduce the existence of the human mind and see it merely as the workings of the brain which is then further reduced to the functions of a computer (Peters, 2012 [13]). Reductionism rules the day. This is deeply misleading and deeply dangerous to kinesiology. As Kretchmar (2005) emphasized, reductionists believe that:

Causal direction always lies in the direction of underlying mechanisms all the way down to the subatomic level. [14] (p. 14)

However, both human experience and clinical practice shows that reductionism has serious limitations for enhancing sport performance or improving health. One such example, is the tendency in western medical practice to view mental illness as a "brain disease" over which the patient has little choice or responsibility (Watters, 2010 [15]). Such fatalism can result in a loss of meaning of which is central to mental well-being.

Nevertheless, materialists continue to insist that empirical data, that which can be measured and quantified, is all that is really needed. This viewpoint is commonly promulgated in the physical sciences and is based upon the authoritative power of mathematics to reveal objective knowledge. As such, many exercise scientists have adopted this approach whereby there has been an over-emphasis on the methods of natural science (Anderson, 2002 [16]). Yet, ironically this is due to exercise scientists' commitments to philosophical materialism. Kinesiologist are often oblivious to non-materialistic conceptions of the field (Twietmeyer, 2015 [17]). The belief of the materialist in mathematics proves the exact opposite of what many materialists think. In fact, mathematics shows that materialism is a self-refuting philosophy. In materialism's rejection of intangibles lays the seeds of its own destruction. As Twietmeyer and Johnson (2018) put it:

Mathematics upon which science relies is an abstract reality which cannot be reduced to matter. Numbers cannot have weight or any other physical property. They are wholly immaterial, yet their reality is necessary to the materialists' project of measuring and counting physical reality. [18] (p. 7)

This philosophic insight shows how deeply problematic materialism is for exercise scientists, despite their commitment to materialism, they routinely rely on the intangibles of mathematics to get their research off the ground.

\section{Examining Accounts of Causation}

The mechanistic picture of nature first put forth by the natural scientists of the seventeenth century which promoted a deterministic view of causality, eventually prompted the counter-assertion that all causes are loose and separate. Thus, it led to the classic problem about causation and induction proposed by David Hume. The Humean perspective is that there is no causative reality in the world other than regularity or what he called "constant conjunction" (Mumford, 2015 [19]). For Hume the cause did not produce the effect. Instead, the effect merely happened to follow the cause. In short, the world was according to Hume, a patchwork of unconnected events (Lewis, 1973 [20]). As distasteful as many find Hume, it should be clear that this naturally follows as a consequence of viewing nature as somehow external to things-themselves. That is, a strictly empiricist metaphysics necessarily results in causal skepticism. This relates to what Aristotelian-Thomist philosopher Edward Feser (2012 [4]) would describe as a case of "as-if teleology". For example, "the chance arrangement of liana vines into a form looking vaguely like a cross, is a case of as-if teleology insofar as the vines were not really arranged for the purpose of representing a cross, but merely to appear as if they were" (p. 5). What Feser means by the notion of as-if teleology is that the movement towards a particular end is not intrinsic to the nature of the thing in question. As such, the fulfillment of a particular end, is a mere 
random occurrence or chance event. To return to the example, it is not of the nature of liana vines to move towards the fulfillment of the end of becoming a symbol like a cross. The view that causation happens accidentally is associated with what Feser describes as "teleological eliminitvism". For the eliminitivist, there is no genuine purposes at all in the natural world. This applies to both the Humean picture of the world and that proposed by the modern scientific mechanists. For the Humean causation is merely arbitrary and for the scientific mechanist it is totally determinate. The crucial difference between the world pictures proposed by the Humean and the scientific mechanist and the Aristotelian picture of the natural world that I am endorsing is that for Aristotle a things nature was inherent to it and it derived its causal power from its own nature. Aristotle argued, this was true of all living things but especially of rational substances, most notably human beings. Rational substances possess the ends towards which they are naturally inclined within themselves in the most perfect possible way. As such, living things are not merely caused to act in a specific way by a set of routine laws imposed upon them from the outside, or by a set of random, external chance occurrences. Another way of viewing all of this centers around the distinction between, on the one hand, those objects that have substantial forms and those having only accidental forms. In rejecting the Aristotelian metaphysical claim that things have- natures, modern, natural science rejected the Aristotelian notion of substantial forms in favor of accidental forms. For Aristotle the objects form was what caused it to be in a specific way. For example, the cause of an object's beauty, was the result of its form, with form being the organizational integrity it exhibits to remain the thing it is. This is known in Aristotelian philosophy as formal causality. Modern, natural science, in contrast, took on the view of causality presupposed by Newtonian mechanics; that is the accidental arrangement and rearrangement of matter in space according to nothing other than physical laws. It could be argued; this was a result of the natural scientists' unwillingness to deal with the puzzles presented by Hume. Newton argued confidently that causes are deterministically connected to their effects. Yet, due to the widespread indifference towards philosophy within exercise science, issues of causality, including conflict between the Newtonian and Humean accounts has largely been ignored. The prevailing Newtonian stance on causation has encouraged exercise scientists to assume that causality moves in a straight line or linear direction. As sport philosopher Scott Kretchmar (2005) explained:

Linearity suggests that doubling a cause (say the length of a lever between the fulcrum and point of force) results in a predictable increase in the effect (the ability to move objects). [14] (p. 15)

Yet, experience shows the limitations of applying such a model to human behavior. Sometimes large causes can lead to small effects. On the other hand, sometimes large effects can proceed from small causes. For example, a small degree of imagination can lead to immense creativity. Or, a large amount of time spent practicing penalty kicks in soccer can have a diminishing return in a shootout due to over-emphasis leading to paralysis of performance, and practice conditions not entirely replicating a match situation, etc.

There is a second common assumption associated with a hard deterministic conception of causality in the sciences, which can also be easily unmasked. That is, that causation only moves in one-direction whereby tangibles effect intangibles, but not vice-versa. Kretchmar (2005) expressed the claim this way:

If ideas are simply the result of a chain of electrical, chemical, physiological and cultural events, then ideas become merely the dependent offspring of the chain. [14] (p. 16)

As one of the leading evangelists of the evolutionary scientific movement Richard Dawkins (1989 [21]) would put it, intangibles like ethics are nothing more than the complex workings of our selfish genes. The irony of this view is that it can be refuted by both philosophy and science. For instance, psychologists at Stanford University, found that just by telling people they have a high or low genetic risk for certain physiological limitations can influence how the person functions when exercising or eating, regardless of what genetic properties or variants they actually have (Turnwald, 
Goyer, Boles, Slider, Delp and Crum, 2018 [22]) As such, ideas have the capacity to change human perception and evaluation concerning the effects of our genetics on behavior. In this sense, ideas can help us overcome supposed physical limitations. Philosophy (ideas) is as important for kinesiology as physiology (genetics).

However, if we accept the predominant views of materialist scientists, we must deny the existence of any values whatsoever (Feser, 2012 [23]). One example of the absurdity of such a position is the reality love. Love is a fundamental reality of human existence, yet materialists explain it away as mere chemicals in the brain (Earp and Savulescu, 2014 [24]). The absurdity doesn't stop there. Respected neuroscientist, Professor Larry Young [25] claims, "it will soon be possible for scientists to develop aphrodisiacs-chemicals that would make people fall in love with the first person they see" (p. 148). Not only is this a denial of all value, it is also a denial of free-will, which is fundamental to the reality of love. The nature of love is as such, that it requires a freely chosen act of self-giving, of one person to another. That is, it can in no way be forced or coerced by outside stimulus and remain what it is. What should be clear from my argument is that the idea of causal determinism is not an adequate explanation of human behavior, and that all philosophic commitments materialistic or otherwise, have significant implications for sub-disciplines in kinesiology such as sport psychology. To reiterate the findings of natural science are not the only legitimate sources of knowledge. What Young is prophesizing is merely another article of crude 'scientism'. In reducing love to chemicals in the brain neuroscientists are attempting to make love an empirically verifiable concept. That is because for reductionists like Young there is no reality beyond that which can be weighed, counted and measured. However, that the human intellect is capable of grasping immaterial concepts such as love should be accepted as the common sense reality that it is. Just because the definition of love possessed by the man on the street is lacking scientific support does not mean there is any reason to doubt its existence. Neither psychological research nor the human beings who participate in it can be coherently reduced to purely material causes. Nonetheless one popular mode of predicting human behavior in the psychological sciences shares the view of deterministic causation held by the materialist scientists. This school of thought is known as behaviorism. Software engineer William. A Wilson (2017) expertly summarized the tenets of behavioral psychology as follows:

Behaviorists believe all human and animal behaviors are merely reactions to external stimuli and previous conditioning. Moreover, they posit the internal states of individuals have no causal effects on their actions, regardless of what those individuals may claim. [26] (pp. 5-6)

In more recent times in sport psychology a cognitive element has been added to the original approach adopted by the behaviorist. Whilst this has provided a belated acknowledgment on behalf of the psychologists of the existence of the human mind cognitions are still by and large viewed in a deterministic fashion. I would argue, the positions taken by the behaviorists and more recently the cognitive behaviorists are detrimental for professional practice in the field of sport psychology and stresses the need to reconsider the appropriate sites of intervention when working with clients. To be sensitive towards such concerns whether (sympathetic or antagonistic) requires respect for philosophy. A pragmatist would likely suggest, for example, that where it works the behaviorists model is fine to use. Nevertheless, I would argue, behaviorism's mistaken views surrounding causality lead behaviorists to incorrectly understand the nature of the human person. As a consequence, behaviorists are likely to encourage among other things, - unethical practice. For example, it may lead a practitioner to deny the free-will of their client through the belief that change occurs solely through altering outside conditions. This is unethical because the faculty of the will is fundamental to our existence as rational animals. Therefore, to prevent the lawful free choice of another human being is to act towards them in a way that is contrary to their rational nature (Feser, 2018 [27]). In addition, numerous studies in sport psychology have demonstrated that the use of prayer by athletes is a common and valuable practice for enhancing performance and overall well-being through supporting the alleviation of stress and anxiety in uncertain situations (Watson and Czech, 2004 [28]; Czech, Wrisberg, Fisher, Thompson and Hayes 2004 [29]; Vernacchia, McGuire, Reardon and Templin, 2000 [30]). All this implies reasons to doubt 
behaviorism. After all, is the well-established effect of prayer on the well-being and the performance of athletes plausibly explained away as self-delusion? Does the fact prayer is both a free endeavor and an immaterial concept provide grounds for dismissing its efficacy? Despite the objections of both materialists and behaviorists, experienced sport psychologists have stated the importance of investigating the possibility of reconciling the use of religious prayer with conventional mental skills training. (Watson and Nesti, 2005 [31]). However, prayer is not just one mere technique amongst all the others. The materialist sport psychologist is ill-equipped to incorporate the use of prayer into their work with clients potentially limiting their overall effectiveness as a consultant. This is because the materialist would in most cases deny the existence of free-will and any form of immaterial reality. As such, they must conclude that the alleged benefits of religious prayer are nothing more than pure fantasy or at the very best mere 'wishful thinking'.

\section{Holism and Waking Exercise Scientists from Their "Philosophic Slumber"}

The value of philosophical holism in kinesiology, and the related non-scientific sub-disciplines of kinesiology should not be undervalued. That is, because holistic practitioners both look globally for partial causes of a problem and are willing to intervene in multiple locations, they do a better job of relating to human beings (Kretchmer, 2005 [14]). Holists realize that the human person is more than the sum of its material parts. Materialists will no doubt disagree. However, such discussion cannot even get off the ground, if exercise scientists fail to recognize the importance of philosophy to the discipline. This is but one example of how philosophy necessarily impinges on the sciences. In contrast to the linear model of causation endorsed by many modern natural scientists, Aristotle viewed causality primarily as hierarchical. As discussed, all of Aristotle's causes stem from beings, and they are found not by simply looking backward in time, but also upward in the chain of responsibility (Sachs, 1995 [3]). An example of a hierarchical causal chain was provided by Feser (2017):

The coldness of the coffee was caused by the coolness in the surrounding air, which was caused by the air conditioner, which was caused to switch on when you pressed the button and so forth. [32] (p. 20)

What this demonstrates is that each of the lower members in a causal chain derive their causal power from a hierarchically higher member. In short, all contingent change requires a changer. What Aristotle went on to conclude was that all such causes derive their causal power from a prime cause. This unmoved mover, as he called it, was identified by Aristotle as God. For present purposes the larger theological implications, can be set aside. The only thing that needs to be emphasized now is that Aristotle argued for an ordered rather than chaotic universe. The things in the cosmos, which had natures unto themselves, were part of a larger whole. Human beings, Aristotle posited, are naturally curious and as a result stretch themselves out toward knowing (Sachs, 1999 [33]). Human beings are not machines, but rather "rational animals" (Aristotle, 2002 [34]). Again, this implies the importance of philosophy as we try to understand, debate and discuss the nature and meaning of this alleged order.

The metaphysical realist position taken by Aristotle in relation to causation is fundamental to the reality and nature of sport and a coherent (and holistic) account of human beings. As philosopher Stephen Mumford (2015 [19]) points out, if there were no causation anything could follow anything else. This has both crude and profound implications. Crudely speaking, this would mean that the football player who scores a touchdown would not be worthy of any credit, as he did not cause the touchdown. More profoundly, if we don't possess something like in-built causal powers, we can claim no responsibility for our actions. As a result, not only would we never be worthy of any praise, neither would we be worthy of any blame. Human responsibility would disappear. Yet, the assumption of human responsibility undergirds all human activity. As sociologists Clifford Staples (2016) put it:

To live in this distinctly human world means holding and being held accountable for what we do, or do not do, against a standard of right and wrong that we alone do not establish and are not free to ignore without consequences. [35] (p. 2) 
As such, to abolish responsibility is to make the world inhuman. It is clear that this has substantial implications in terms of professional ethics for all disciplines within kinesiology. Yet again the importance of philosophy is demonstrated. For if free-will is to be jettisoned, the commitment should be made deliberately rather than as a cavalier result of previous unacknowledged philosophic commitments.

It also follows from the model of causation proposed by materialistic science that all sporting outcomes are necessitated. This would make sport dull to watch and pointless to play (Mumford, 2015 [19]). We would lose the mystery, serendipity and human drama of sport which is a primary reason so many of us are attracted to it. As Mumford (2015) argues, the reality of sporting contests proposes the existence of a causal efficacy that lies somewhere in between arbitrary and deterministic causality.

It is arguable that sport is premised on there being a modal strength that is less than necessity but more than mere possibility; an intermediate dispositional modality in which sporting abilities tend towards outcomes without guaranteeing them. [19] (p. 282)

What Mumford means is that- the best team or individual wins most of the time, but not all the time. Though chance and fortune should both play a part, skill should by and large be the determinative factor. What is clear from these examples, is that one's philosophic commitments matter at both the theoretical and practical levels. Ignoring the philosophical conclusions of materialism do not make them go away.

Aristotelian philosophy offers a viable alternative in kinesiology to the accounts of causation provided by modern, natural science. If we recover his notion of "nature" or final causality, we will be able to view the discipline primarily in light of the end's values associated with it. That is, as Kretchmar (2005 [14]) insisted, we will be able to consider kinesiology as a jewel rather than as merely a tool. Too often the discipline is focused on selling itself on the basis of its usefulness. In short, we limit our contribution to human health. Yet, as Twietmeyer and Johnson (2018 [18]) put it, "nobody lives for health. Rather they live from health toward the world of love, play, family, career, and so forth" (p. 8). In this sense, we are selling ourselves short. Exercise science is a powerful and indispensable resource for understanding the biological and physiological nature of human movement, but it is still just a tool, which must be put in service of some further good or end. To adjudicate these ends, to debate what we ought to do, to see and understand the good requires philosophy, not further measurement.

In denying the proper relation of means to ends we have followed the lead of modern, natural science which reduced Aristotle's final cause to a mere series of efficient causes. From Aristotle's point of view, this is incoherent. To reject the idea that things are directed to certain ends or goals by virtue of their nature, is to render efficient causality as unintelligible (Feser, 2010 [36]). For example, human beings have feet in order to walk, without this function, having feet as part of the human anatomy would make very little sense. Therefore, despite many natural scientist's rejection of final causality, they attempt to smuggle it in through the backdoor via the affirmation of efficient causes. Moreover, our over-emphasis on health encourages kinesiologists to take the view that matter is all that really exists. In other words, we have taken human embodiment too seriously. For many kinesiologists "we are just bodies".

This view of human embodiment in the exercise sciences which is so common, aligns with the currently dominant cultural paradigm. Materialism rules the day. As physical educator Brian Pronger (1995 [37]) explained, "the body is a malleable, useful object in modern culture" (p. 428). Kinesiologists must reject thinking such as this. Just as embodiment is part of the larger human whole, kinesiologists must discover a larger sense of the whole in the discipline of which each sub-discipline is merely a part. Exercise science and sport philosophy need each other. This acknowledgment is vital, both for the sake of attaining a true conception of kinesiology and for a true conception of our clients, students, athletes and research subjects. Human beings are not mere atoms in motion, nor are they incorporeal minds for whom embodiment and chemistry and genetics and physiology do not matter. This insight relies not on measurement but rather reflection. To do scientific research in kinesiology 
well requires philosophy because those of whom we serve, as well as all kinesiologists themselves are more than mere bodies.

Funding: This research received no external funding.

Acknowledgments: The author would like to acknowledge both reviewers for their helpful and insightful comments.

Conflicts of Interest: The author declares no conflict of interest.

\section{References}

1. Wilson, M. From processing efficency to attentional control: A mechanistic account of the anxiety-performance relationship. Int. Rev. Sport Exerc. Psychol. 2008, 1, 184-201. [CrossRef]

2. Ronkainen, N.; Nesti, M. An existential approach to sport psychology: Theory and applied practice. Int. J. Sport Exerc. Psychol. 2015, 15, 12-24. [CrossRef]

3. Sachs, J. Introduction. In Aristotle, Aristotles Physics; Rugters University Press: London, UK, 1995.

4. Feser, E. Atheistic Teleology? Available online: http://edwardfeser.blogspot.com/2012/07/atheistic-teleology. html (accessed on 5 July 2012).

5. Sachs, J. On the soul: An introduction. In Aristotle, On the Soul, Memory and Recollection; Green Lion Press: Santa Fe, NM, USA, 2001.

6. Midgley, M. Science as Salvation: A Modern Myth and its Meaning; Routledge: New York, NY, USA, 1992.

7. Brown, M. The case for perfection. J. Philos. Sport 2009, 36, 127-139. [CrossRef]

8. Lewis, C.S. Christian Reflections; Eerdmans: Grand Rapids, MI, USA, 1967.

9. Ratzinger, J. Apostolic Journey of his holiness Benedict XVI to Munchen, Altoting and Regensburg. Available online: http://w2.vatican.va/content/benedict-xvi/en/speeches/2006/september/documents/hf_benxvi_spe_20060912_universityregensburg.html (accessed on 9 September 2006).

10. Pieper, J. An. Anthology; Ignatius Press: San Francisco, CA, USA, 1989.

11. Nagel, T. Mind and Cosmos: Why the Materialist Neo-Darwinan Conception of Nature is Almost Certainly False; Oxford University Press: Oxford, UK, 2012.

12. Cave, S. There's No Such Thing as Free-Will. Available online: https://www.theatlantic.com/magazine/ archive/2016/06/theres-no-such-thing-as-free-will/480750/ (accessed on 2 June 2016).

13. Peters, S. The Chimp Paradox: The Aclaimed Mind Management Programme to Help You Achieve Success, Confidence and Happiness; Tarcher Penguin: New York, NY, USA, 2012.

14. Kretchmar, R.S. Practical Philosophy of Sport and Physical Activity; Human Kinetics: Champaign, IL, USA, 2005.

15. Watters, E. The Americanization of Mental Illness. Available online: https://www.nytimes.com/2010/01/10/ magazine/10psyche-t.html (accessed on 10 January 2010).

16. Anderson, D. The humanity of movement or"its not just a gym class". Quest 2002, 54, 87-96. [CrossRef]

17. Twietmeyer, G. God, sport, philosophy, kinesiology: A MacIntyrean investigation. Quest 2015, 67, 203-226. [CrossRef]

18. Twietmeyer, G.; Johnson, T. A kinesiology conundrum: Physical activity requirments in kinesiology degree programs. Quest 2018, 71, 90-111. [CrossRef]

19. Mumford, S. Metaphysics and Sport. In Morgan and McNamee, The Routledge Hanbook of the Philosophy of Sport; Routledge: Abingdon, UK, 2015.

20. Lewis, D. Counterfactuals; Blackwell Publishing: Oxford, UK, 1973.

21. Dawkins, R. The Selfish Gene; Oxford University Press: Oxford, UK, 1989.

22. Turnwald, B.; Goyer, P.; Boles, D.; Slider, A.; Delp, S.; Crum, A. Learning one's genetic risk changes physiology independent of actual genetic risk. Nat. Hum. Behav. 2018, 3, 48-56. [CrossRef] [PubMed]

23. Feser, E. Aristotle, Call Your Office. Available online: https:/www.firstthings.com/web-exclusives/2012/10/ aristotle-call-your-office (accessed on 18 October 2012).

24. Earp, B.; Savulescu, J. Love drugs: Why Scientists Study the Effects of Pharmaceuticals on Human Romantic Relationships; Cambridge University Press: Cambridge, UK, 2014.

25. Young, L. Being human: Love: Neuroscience reveals all. Nat. Int. J. Sci. 2009, 457, 148.

26. Wilson, A.W. The Myth of Scientific Objectivity. Available online: https://www.firstthings.com/article/2017/ 11/the-myth-of-scientific-objectivity (accessed on 12 November 2017). 
27. Feser, E. Violence in Word and Action. Available online: http://edwardfeser.blogspot.com/2018/10/violencein-word-and-action.html (accessed on 27 October 2018).

28. Watson, N.; Czech, D. The use of prayer in sport: Implications for sport psychology consulting. Athl. Insight 2005, 7, 26-35.

29. Czech, D.; Wrisberg, C.; Fisher, L.; Thompson, C.; Hayes, G. The experience of Christian prayer in sport: An existential phenomenological investigation. J. Psychol. Christ. 2004, 23, 3-11.

30. Vernacchia, R.; McGuire, R.; Reardon, J.; Templin, D. Psychosocial characteristics of olympic track and field athletes. Int. J. Sport Psychol. 2000, 31, 5-23.

31. Watson, N.; Nesti, M. The role of spirituality in sport psychology consulting: An analysis and integrative review of literature. J. Appl. Sport Psychol. 2005, 17, 228-239. [CrossRef]

32. Feser, E. Five Proofs of the Existence of God; Ignatius Press: San Francisco, CA, USA, 2017.

33. Sachs, J. Introduction in Aristotle, Aristotle's Metaphysics; Green Lion Press: Santa Fe, NM, USA, 1999.

34. Aristotle. Nicomachean Ethics; Focus Philosophical Library: Newbury, MA, USA, 2002.

35. Staples, C. Abolishing the Moral Order. Available online: https://www.crisismagazine.com/2016/abolishingmoral-order (accessed on 15 December 2016).

36. Feser, E. Teleology a shoppers guide. Philos. Christi 2010, 12, 142-159. [CrossRef]

37. Pronger, B. Body Facism: Salvation in the Technology of Physical Fitness; University of Toronto Press: Toronto, CN, Canada, 2002.

(C) 2019 by the author. Licensee MDPI, Basel, Switzerland. This article is an open access article distributed under the terms and conditions of the Creative Commons Attribution (CC BY) license (http://creativecommons.org/licenses/by/4.0/). 